\title{
A MULTIFUNCIONALIDADE DA PAISAGEM RURAL NO MUNICÍPIO DE ARROIO DO PADRE-RS
}

\author{
Arlene FEHRENBACH \\ Giancarla SALAMONI
}

\section{Resumo}

O presente estudo pretende contribuir para a discussão acerca da multifuncionalidade da agricultura relacionando as múltiplas funções presentes no espaço rural. Considera-se que o espaço geográfico está em permanente transformação e, para o entendimento de uma das funções da agricultura, a conservação dos recursos naturais e da paisagem rural, é necessário adotar procedimentos teórico-metodológicos que permitam uma abordagem abrangente sobre tema de tal complexidade. Diante disso, o estudo sobre o município de Arroio do Padre/RS foi elaborado mediante revisão bibliográfica sobre o conceito de multifuncionalidade, caracterização da área de estudo por meio de dados secundários e de registros fotográficos dos compartimentos geomorfológicos presentes no município. Através deste estudo preliminar, foi possível constatar as diversas modificações que ocorreram na paisagem rural e as relações com as atividades agrícolas desenvolvidas pela agricultura familiar.

Palavras-chave: Paisagem. Espaço rural. Agricultura familiar.

\section{Abstract \\ The multifunctionality of the rural landscape in the municipality of Arroio do Padre-RS}

The present study intends to contribute to the discussion among the multifunctionality of agriculture relating the multiple functions present in the rural space. It is considered that the geographic space is in permanent transformation and for the understanding of one of the functions of agriculture, the conservation of natural resources and the rural landscape, it is necessary to adopt theoretical and methodological procedures that allow a comprehensive approach on the subject of such complexity. Therefore, the study on the municipality of Arroio do Padre/RS was elaborated through a bibliographical review about the concept of multifunctionality, characterization of the study area by means of secondary data and photographic records of the geomorphological compartments present in the municipality. Through this preliminary study, it was possible to verify the several modifications that occurred in the rural landscape and the relations with the agricultural activities developed by the family farming.

Key words: Landscape. Rural space. Family farming.

\footnotetext{
1 Graduanda em Bacharelado em Geografia - UFPel. Bolsista Iniciação Científica CNPq. ICHUFPel. Rua Coronel Alberto Rosa, 154, Centro - Pelotas/RS. CEP. 96010-770. E-mail: arlenefehrenbach@outlook.com

2 Professora Doutora na Universidade Federal de Pelotas (UFPel). ICH-UFPel. Rua Coronel Alberto Rosa, 154, Centro - Pelotas/RS. CEP. 96010-770. E-mail: gi.salamoni@yahoo.com.br
} 


\section{INTRODUÇÃO}

O espaço rural vem sofrendo diversas modificações ao longo do tempo e, a partir de 1990, percebe-se a valorização de novas funções relacionadas à agricultura brasileira. Assim, o país acaba adotando o conceito de multifuncionalidade da agricultura, tendo como referência os estudos realizados no continente europeu, cenário que se destaca por inúmeros debates acadêmicos e pela proposição de políticas públicas, a fim de se reconhecer o caráter multifuncional existente na agricultura. No Brasil, a difusão do conceito se deu por meio da adoção de políticas públicas de apoio e fortalecimento da agricultura familiar.

Para Carneiro e Maluf (2003, p. 21), a noção de multifuncionalidade é "um 'novo olhar' sobre a agricultura familiar, que permite analisar a interação entre famílias e territórios na dinâmica de reprodução social." Assim sendo, estes autores definiram as quatro funções ligadas à multifuncionalidade da agricultura familiar dentro do contexto brasileiro: 1) Reprodução socioeconômica das famílias rurais; 2) Promoção da segurança alimentar das próprias famílias rurais e da sociedade; 3) Manutenção do tecido social e cultural; e 4) Conservação dos recursos naturais e da paisagem rural.

Neste trabalho, serão caracterizadas as quatro funções da multifuncionalidade, enfatizando-se a última função devido à necessidade de compreender as alterações causadas pela agricultura na paisagem no contexto do município de Arroio do Padre/ RS. Assim, o conceito de paisagem torna-se primordial para o estudo, e a análise da "paisagem rural completa-se com, por um lado, a avaliação da procura de todos os tipos de funções e, por outro, a avaliação de como o uso do solo (através da agricultura ou outras atividades) afeta as várias funções e como elas se relacionam entre si." (PINTO-CORREIA, 2007, p. 69).

Cabe destacar que o presente trabalho faz parte de um projeto de maior abrangência, intitulado Multifuncionalidade na organização do espaço pela agricultura familiar: abordagens comparativas sobre a paisagem rural nos estados de MG, RS, e $S P$, que tem como escala de análise estudos de caso realizados nos referidos estados, os quais possuem diferentes contextos histórico-espaciais. Diante disso, a fim de realizar análises comparativas no que diz respeito à multifuncionalidade da agricultura familiar, foram propostos parâmetros norteadores ${ }^{3}$ para os estudos em tela.

\section{METODOLOGIA}

De acordo com Verdum et al. (2016), a paisagem é um sistema aberto, e sua análise pode ser dada em duas perspectivas: a paisagem concreta, que seriam as marcas da ação humana na superfície terrestre no decorrer do tempo, destacando duas variáveis, o tempo e a materialidade; e a paisagem fenomenológica, que reside nos diferentes "modos do sujeito olhar, interpretar e transformar o espaço geográfico." (VERDUM et al., 2016, p. 133). Para tanto, essas duas abordagens são

\footnotetext{
3 Ver sobre a proposição de parâmetros para a análise das funções da agricultura familiar em KONZGEN, Q. R. S. A multifuncionalidade nos espaços da agricultura familiar: um estudo de caso na localidade da Glória - $1^{0}$ distrito do município de Canguçu/RS. 2017. 128 f. Trabalho de Conclusão de Curso (Licenciatura em Geografia) - Universidade Federal de Pelotas, Pelotas, 2017.
} 
indissociáveis, pois as formas materiais e imateriais estão em constante interação na paisagem rural.

Para a elaboração deste estudo, primeiramente foi realizada uma revisão bibliográfica acerca do tema da multifuncionalidade e do município em questão no que se refere à paisagem rural. Em seguida, para melhor caracterização da área de estudo, foi feito um levantamento de dados secundários. Por fim, foi efetuado levantamento fotográfico de cada compartimento geomorfológico de Arroio do Padre, com a finalidade de obter uma interpretação da paisagem rural do município em estudo por meio da análise das fotografias. Além disso, está prevista a realização de entrevistas com agricultores familiares para aprofundar a caracterização dos elementos que compõem a paisagem rural.

\section{CARACTERIZAÇÃo DA ÁREA DE ESTUDO}

O município de Arroio do Padre (Figura 1) está localizado na região sul do estado do Rio Grande do Sul, fazendo parte da Mesorregião Sudeste Rio-Grandense e da Microrregião de Pelotas, com uma área equivalente a 124,317 Km². Trata-se de um município relativamente jovem, que foi emancipado de Pelotas em 17 de abril de 1996, tendo como característica a predominância da agricultura familiar. A maioria dos 2.730 habitantes do município reside da zona rural, conformando $83,37 \%$ da população, e apenas $16,63 \%$ do total é residente da zona urbana (IBGE, 2010).

A economia do município está intimamente ligada à agricultura, com o predomínio de pequenas propriedades que apresentam um caráter de agricultura familiar, visto que existem 486 estabelecimentos familiares e apenas 21 patronais no município (IBGE, 2006). De acordo com Kerstner (2013), a principal atividade agrícola existente é a do tabaco, mas destacam-se também os cultivos de soja, feijão, milho, legumes, frutas e áreas de pastagens. A autora ainda ressalta a ocorrência de desmatamento no município, restando poucas áreas de mata nativa, assim como uma gradual introdução de espécies exógenas, principalmente o eucalipto, mas também de acácia e pinus. 


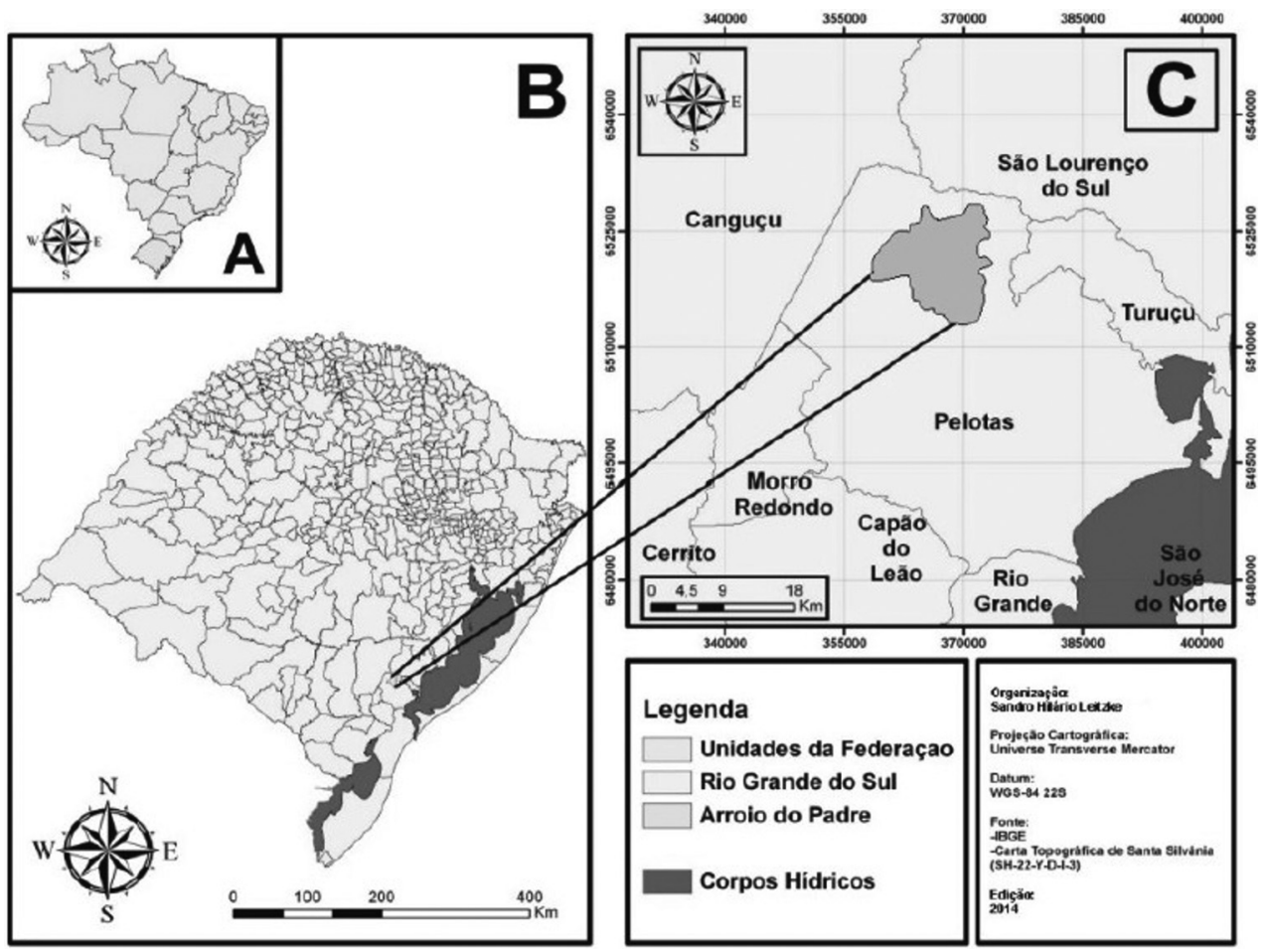

Figura 1 - Mapa de localização do município de Arroio do Padre/RS

Fonte: Prefeitura Municipal de Arroio do Padre, 2014.

\section{PRESSUPOSTOS TEÓRICOS ACERCA DA MULTIFUNCIONALIDADE}

A noção de multifuncionalidade da agricultura apareceu pela primeira vez na década de 1990, tendo como referência os debates ocorridos na Conferência Rio-92 que discutiram o desenvolvimento sustentável relacionado à agricultura e ao meio rural. A partir de então, observou-se a valorização de novas funções ligadas à agricultura familiar, inicialmente associada ao turismo no espaço rural.

Destaca-se que a Europa é referência no debate sobre a noção de multifuncionalidade da agricultura, dado que vários países do continente foram objeto de estudos e pesquisas acerca do tema, e também no reconhecimento desta noção por meio da criação de políticas públicas. Tomando-se o exemplo da França, a tentativa de aplicação da validade do conceito se deu por meio dos chamados contratos territoriais ${ }^{4}$ estabelecidos entre o Estado e os agricultores (CARNEIRO; MALUF, 2003).

\footnotetext{
${ }^{4}$ Os Contratos Territoriais de Estabelecimento (CTEs) já foram extintos, mas estes se resumiam basicamente em um contrato entre agricultores e o Estado, para a viabilização de um projeto de desenvolvimento econômico dos estabelecimentos agropecuários, relacionados ao ambiente e à manutenção da paisagem rural, e os agricultores se comprometiam em desempenhar compromissos relacionados à sua unidade de produção. Ver mais em Gavioli e Costa (2011).
} 
No enfoque brasileiro, destaca-se um convênio entre pesquisadores franceses e brasileiros que desencadeou o projeto intitulado Estratégias de desenvolvimento rural, multifuncionalidade da agricultura e a agricultura familiar: identificação e avaliação de experiências em diferentes regiões brasileiras, com o objetivo de "explorar as possibilidades oferecidas pela noção de multifuncionalidade da agricultura, face às peculiaridades da realidade rural brasileira, com vistas a definir [...] desdobramentos para a formulação de políticas públicas" (CARNEIRO; MALUF, 2003, p. 12). Essa pesquisa se deu acerca de três níveis de análise: as famílias rurais, o território e a sociedade. Sendo assim:

A noção de multifuncionalidade rompe com o enfoque setorial e amplia o campo das funções sociais atribuídas à agricultura, que deixa de ser entendida apenas como produtora de bens agrícolas. Ela se torna responsável pela conservação de recursos naturais (água, solos, biodiversidade e outros), do patrimônio natural (paisagens) e pela qualidade dos alimentos (CARNEIRO; MALUF, 2003, p. 19).

Nas suas análises e observações a respeito da multifuncionalidade da agricultura familiar, Carneiro e Maluf (2003) definiram quatro funções, a saber:

1) Reprodução socioeconômica das famílias rurais: diz respeito à geração de trabalho e renda capaz de permitir que as famílias rurais continuem a permanecer no campo em condições dignas, ressaltando que a agricultura ainda continua a desempenhar um papel importante dentro da reprodução econômica da famílias rurais. Porém, vem crescendo o número de famílias em que a renda monetária proveniente da produção agrícola é a menos importante, destacando-se assim a pluriatividade ${ }^{5}$, mas com atividades enraizadas dentro da agricultura, como o turismo rural e agroindústria;

2) Promoção da segurança alimentar das famílias e da sociedade: condiz com a produção para autoconsumo e comercialização, pois a agricultura familiar promove a segurança alimentar no sentido da disponibilidade e acesso aos alimentos, e também de sua qualidade.

3) Manutenção do tecido social e cultural: refere-se à identidade social e às diversas formas de sociabilidade das famílias e das comunidades rurais. Aqui a agricultura é entendida como um modo de vida, o qual é valorizado perante os agricultores, mas visto de forma pessimista em relação ao futuro.

4) Conservação dos recursos naturais e da paisagem rural: está intimamente ligada ao uso de recursos naturais e à sua preservação, sendo observadas as relações entre atividades econômicas e paisagem. O debate acerca desta função ainda é bastante incipiente, sendo necessária assim uma maior expansão, por meio da qual se possam reconhecer as transformações ocorridas no patrimônio natural.

Portanto, constatando a necessidade de desenvolver novas abordagens acerca da multifuncionalidade da paisagem rural, concorda-se com os dois eixos de compreensão estabelecidos por Pinto-Correia (2007), que se desenrolam ligados entre si:

1) Uma composta pela integração entre a base física e biológica e a influência e construção humana, ao longo do tempo, resultando na materialidade da paisagem, com as suas potencialidades e limitações, assim como no seu carácter, ou identidade; 2) e uma outra composta pela cadeia de relações

\footnotetext{
${ }^{5}$ Combinação de atividades agrícolas e não agrícolas desempenhadas pelas famílias de agricultores.
} 
socioeconômicas e condições culturais que determinam as condições sobre a paisagem; este eixo contempla aspectos que vão desde a economia global e a procura social em geral, até as políticas e instrumentos de gestão, o contexto local e o perfil individual de quem toma decisões no cotidiano sobre a gestão ou sobre o uso da paisagem (PINTO-CORREIA, 2007, p. 69).

Oliveira et al. (2008) dizem que o estudo da paisagem é um conceito complexo que pode ser analisado a partir de múltiplas perspectivas. Assim,

[...] a paisagem pode ser encarada em simultâneo como o contexto onde o processo de mudança ocorre, considerando a dinâmica espacial e temporal que lhe é inerente. Pode também ser o âmbito do estudo desse processo e constituir-se como a base para o ordenamento e gestão dos recursos e atividades que a caracterizam (OLIVEIRA et al., 2008, p. 4-5).

Seguindo essas concepções, observa-se que o conceito de multifuncionalidade da paisagem oferece maiores possibilidades de caracterização de tal paisagem rural, almejando orientações a seu ordenamento e sua gestão. Partindo dessas premissas, a discussão a seguir abordará a multifuncionalidade da paisagem rural do município de Arroio do Padre, tendo em vista que, para sua melhor identificação, serão utilizados os compartimentos geomorfológicos como unidades de paisagem.

\section{O CARÁter multifuncional dA PAISAgem RURAL DE ARROIO DO PADRE}

A paisagem rural do município de Arroio do Padre é analisada a partir dos compartimentos geomorfológicos, conforme pode ser visualizado no mapa (Figura 2) elaborado por Meurer e Flach (2015).

De acordo com o Plano Ambiental Municipal (2014), a vegetação nativa de Arroio do Padre corresponde atualmente a cerca de $42 \%$ da área do município e encontra-se situada basicamente em áreas mais íngremes e com declividades acentuadas, e o restante da área é ocupado pela agricultura. Ressalta-se que as áreas mais elevadas, com solos rasos e afloramentos rochosos, não possuem recomendação para seu uso pela agricultura; apenas podem ser utilizadas em culturas anuais as áreas menos íngremes de relevo ondulado. A principal atividade agrícola é o cultivo de tabaco, como já destacado, porém o cultivo de hortaliças e a fruticultura também aparecem. Destaca-se que, nos últimos anos, houve um aumento significativo no plantio de soja na área que abrange o município.

No levantamento fotográfico, realizado em julho de 2017, não foi possível fazer uma análise aprofundada da paisagem, pois o uso da terra para a agricultura encontrava-se em período de pousio, predominando, assim, a pastagem utilizada para alimentar o gado e/ou como técnica de conservação do solo.

O compartimento geomorfológico Planaltos Residuais Canguçu-Caçapava do Sul se caracteriza por ser a porção mais elevada que domina toda a porção oeste do município, com a predominância da forma de relevo de topo convexo com baixas declividades, e também por possuir a maior extensão territorial. O solo é pouco espesso, sendo desfavorável à agricultura, pois favorece o escoamento superficial e potencializa os processos erosivos. Como se pode observar na Figura 3, neste compartimento encontra-se a presença de plantação de hortaliças e de pastagem. Ocorre, ainda, a presença de mata nativa e espécies exógenas (eucalipto e pinus). 


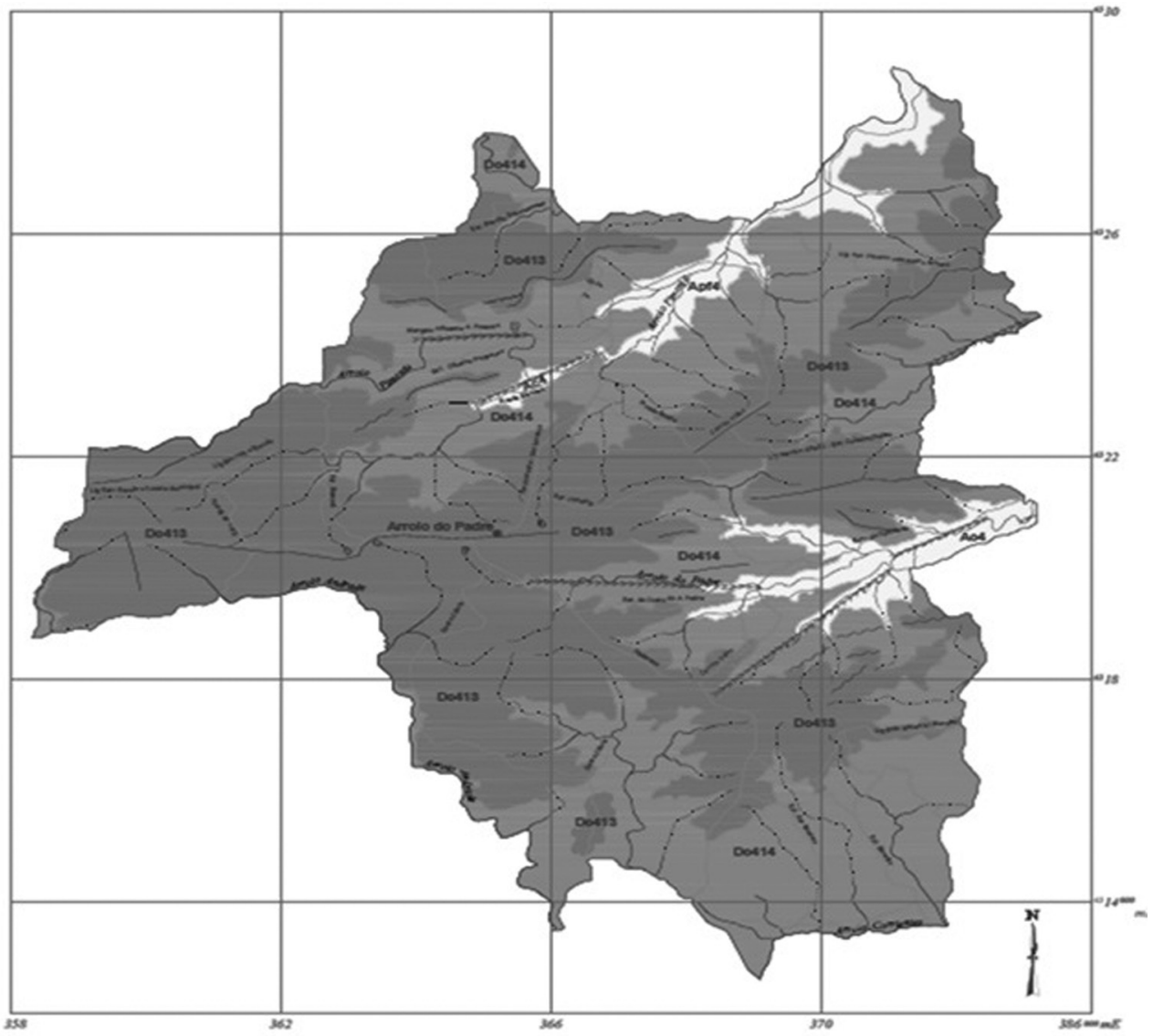

\begin{tabular}{|c|c|c|}
\hline $\begin{array}{l}\text { DOMiNIOS MORFOESTRUTURAIS } \\
\text { (1 } 1^{\circ} \text { Taxon) }\end{array}$ & $\begin{array}{l}\text { REGIOES GEOMORFOLOGICAS } \\
\text { (20 Taxon) }\end{array}$ & $\begin{array}{l}\text { UNIDADES GEOMORFOLOGICAS } \\
\text { (3॰ Taxon) }\end{array}$ \\
\hline I - DEPOSITOS SEDIMENTARES & PLANICIE CONTINENTAL & Planicle AUUvio-Coluvionar \\
\hline $\begin{array}{l}\text { III- EMBASAMENTOS EM ESTILOS } \\
\text { CONPLEXOS }\end{array}$ & PLANALTO SUL-FIOGRANDENSE & $\begin{array}{l}\text { Planato Reoabcado Marginal } \\
\text { Planaltos Residuals Cangugu-Caçapava } \\
\text { do Sul }\end{array}$ \\
\hline
\end{tabular}

Figura 2 - Mapa geomorfológico do município de Arroio do Padre/RS Fonte: Meurer e Flach, 2015. 


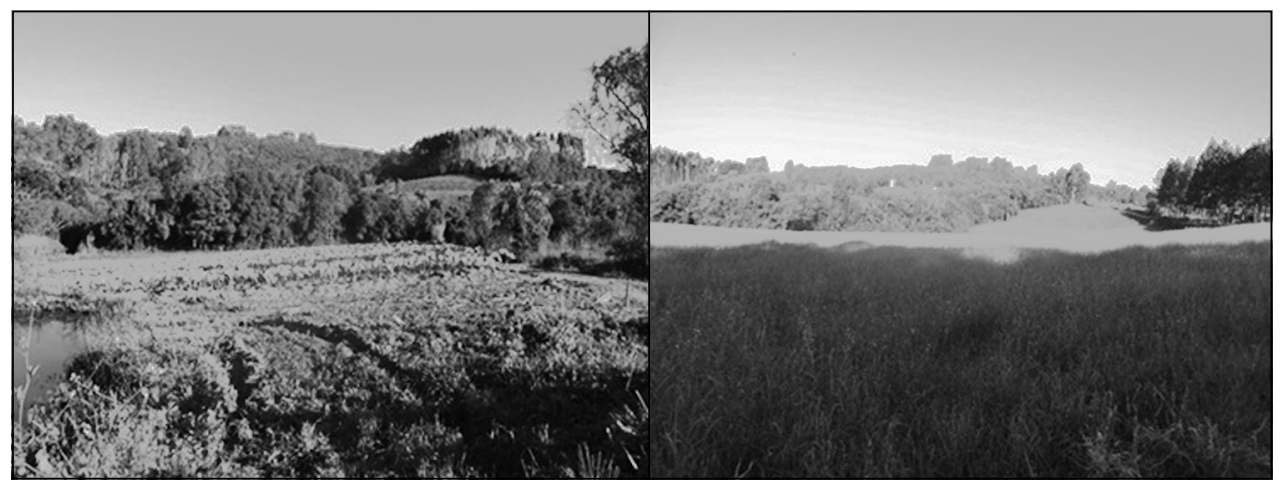

Figura 3 - Planaltos Residuais Canguçu-Caçapava do Sul

Fonte: Pesquisa de Campo, 2017.

O Planalto Rebaixado Marginal corresponde à área "mais dissecada da borda da região geomorfológica do Planalto Sul-Riograndense" (MEURER; FLACH, 2015, p. 317), e no interior desta unidade ocorre a formação de morros e colinas com alta declividade e, como na unidade anterior, possui grande predisposição para a erosão. No compartimento (Figura 4), observam-se a predominância da pastagem, a ocorrência de hortas para o autoconsumo das famílias rurais e plantações de eucalipto. Destaca-se que a madeira oriunda deste tipo de plantação serve de combustível para as estufas de secagem do tabaco no pós-colheita.

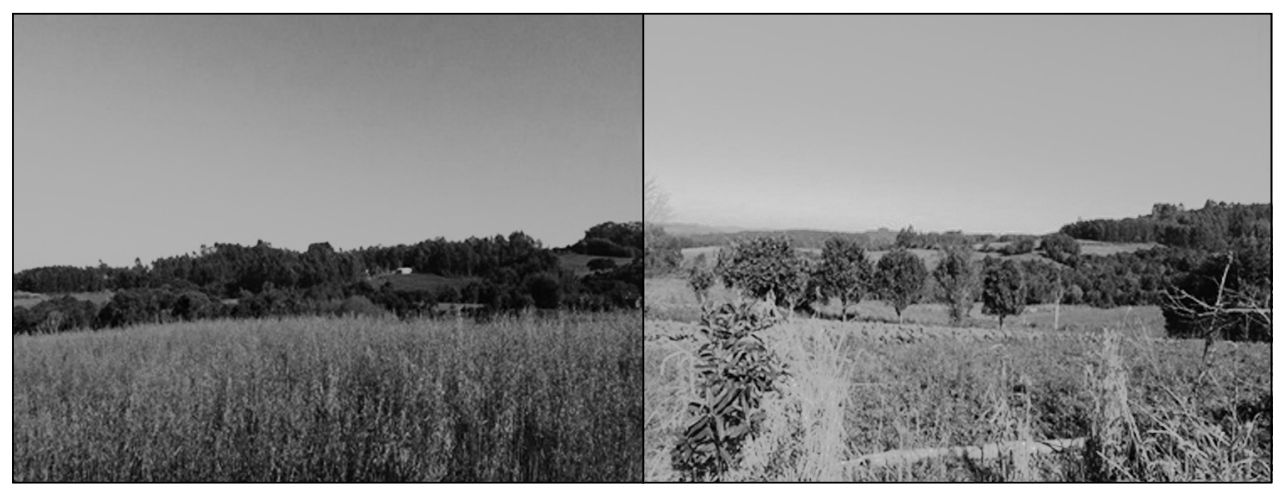

Figura 4 - Planalto Rebaixado Marginal

Fonte: Pesquisa de Campo, 2017.

Por fim, tem-se a unidade geomorfológica Planície Alúvio-Coluvionar, compreendendo as áreas mais baixas do município, das bacias do Arroio do Padre e do Arroio Pimenta, as quais se caracterizam pela acumulação de sedimentos e se subdividem em dois modelados: modelado de acumulação coluvial ou de enxurrada (bacia do Arroio Pimenta) e modelado de acumulação em planície fluvial (bacia do Arroio do Padre).

Na bacia do Arroio Pimenta (Figura 5), observa-se a utilização do patrimônio natural para o desenvolvimento de atividades turísticas, destacando a Cachoeira do 
Camboatá, que, de acordo com o Plano Ambiental Municipal (2014), é um dos principais atrativos turísticos do município. Ainda, como nos demais compartimentos, ocorre a presença de pastagem para o gado leiteiro e de espécies exógenas como o eucalipto.

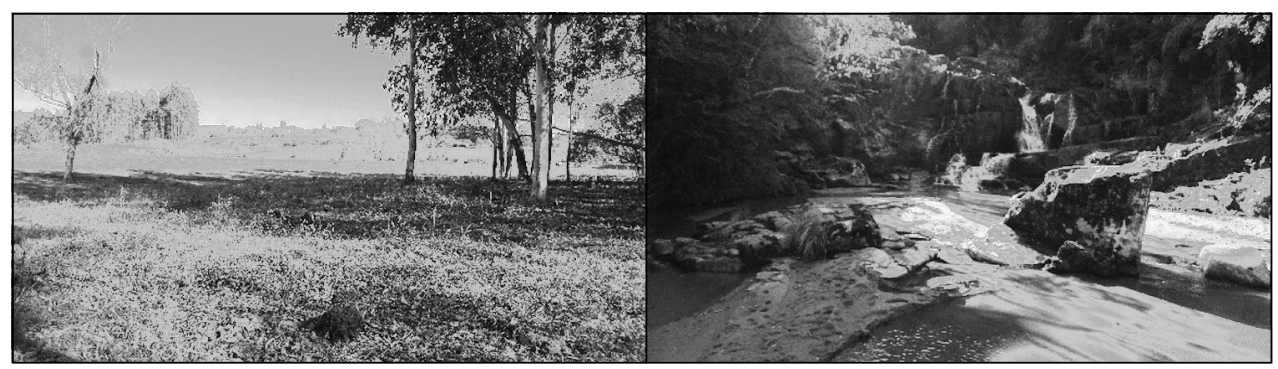

Figura 5 - Modelado de Acumulação Coluvial ou de Enxurrada

Fonte: Pesquisa de Campo, 2017.

Na bacia do Arroio do Padre (Figura 6), foi observada uma ocupação da paisagem rural de forma semelhante aos demais compartimentos, ou seja, pastagens e matas exógenas, principalmente.

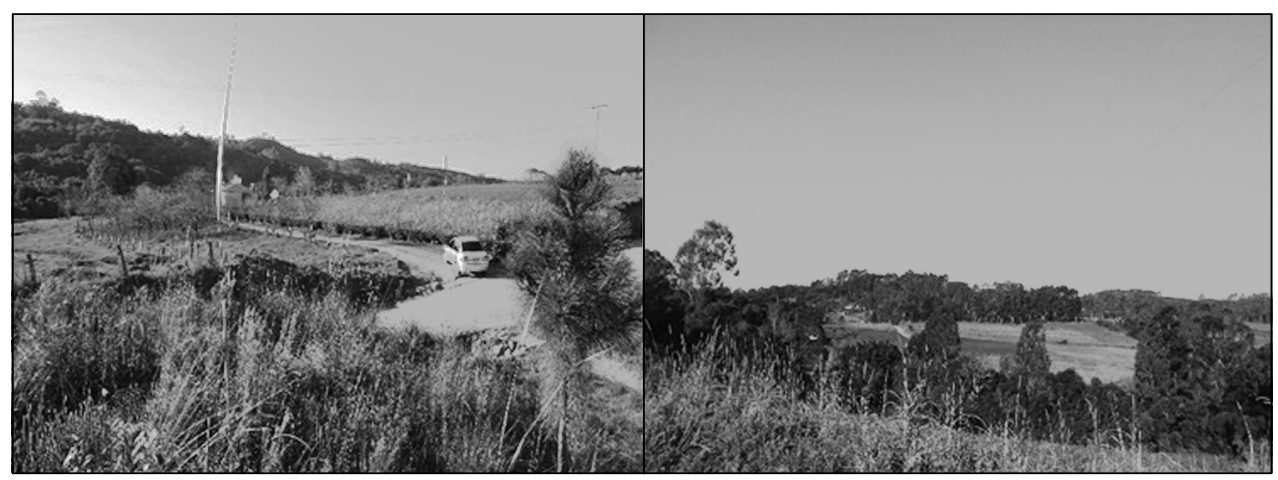

Figura 6 - Modelado de Acumulação em Planície Fluvial

Fonte: Pesquisa de Campo, 2017.

Cabe ressaltar que a análise sobre a conservação dos recursos naturais e da paisagem rural do município precisa ser efetuada de modo mais aprofundado. De antemão, pode-se afirmar que a agricultura vem acarretando inúmeras transformações na paisagem no decorrer dos anos, e entender este processo é crucial para que ocorra um planejamento eficaz sobre o uso da terra e gestão dos recursos naturais, uma vez que o município se configura num verdadeiro mosaico de paisagens agrárias:

Observando a paisagem do município de Arroio do PadreRS, é notável a diversificação nos usos da terra, representada pelas lavouras de fumo, milho, feijão, pastagens, campos, matas, pela arquitetura das casas. Deste modo, a pai- 
sagem natural e cultural conformam uma unidade geográfica, representando as formas de uso e ocupação histórica, uma vez que a paisagem natural já foi, parcialmente, modificada pela ação humana (KERSTNER, 2013, p. 80).

\section{CONCLUSÃO}

Para não encerar o debate sobre o caráter multifuncional da paisagem rural do município, entende-se que Arroio do Padre, por ser um município predominantemente rural e apresentar como característica a presença da agricultura familiar, é o lócus privilegiado para aplicação da noção de multifuncionalidade da agricultura, particularmente no que diz respeito à conservação dos recursos naturais e da paisagem rural, pois esta já sofreu diversas alterações ao longo do tempo. A análise realizada por meio de levantamento fotográfico dos compartimentos geomorfológicos não é suficiente para compreender a complexidade da dinâmica de uso do espaço rural, porém sabe-se que a paisagem rural está inserida, cada vez mais, no sistema capitalista, o qual acelera as transformações com o incremento do meio técnicocientíficoinformacional. Acredita-se que os agricultores familiares de Arroio do Padre incorporaram o processo de modernização em suas atividades agrícolas, entretanto, não operam unicamente pelos princípios da lógica econômica, pois não consideram a propriedade da terra apenas como um bem com valor monetário, mas como patrimônio simbólico-cultural, associado à manutenção de saberes e práticas de gestão dos recursos naturais e da paisagem rural. Nesse sentido, a paisagem é entendida como produto cultural do modo de vida desse grupo social.

\section{REFERÊNCIAS}

CARNEIRO, M. J.; MALUF, R. S. (Org.). Para além da produção: multifuncionalidade e agricultura familiar. Rio de Janeiro: MAUAD, 2003.

GAVIOLI, F. R.; COSTA, M. B. B. As Múltiplas Funções da Agricultura Familiar: um estudo no assentamento Monte Alegre, região de Araraquara (SP). Rev. Econ. Sociol. Rural, Brasília, v.49, n.2, p.449-472, 2011.

INSTITUTO BRASILEIRO DE GEOGRAFIA E ESTATÍsTICA (IBGE). Censo Agropecuário, 2006. Disponível em: <http://www.ibge.gov.br>. Acesso em: 17 ago. 2017.

INSTITUTO BRASILEIRO DE GEOGRAFIA E ESTATÍSTICA (IBGE). Censo Demográfico, 2010. Disponível em: <http://www.ibge.gov.br>. Acesso em: 17 ago. 2017.

KERSTNER, J. V. Análise-Diagnóstico de Sistemas Agrários: um estudo sobre a agricultura familiar no município de Arroio do Padre-RS. 2013. 99f. Monografia (Graduação em Geografia) - Instituto de Ciências Humanas, Universidade Federal de Pelotas, 2013.

MEURER, M.; FLACH, C. W. A geomorfologia do município de Arroio do Padre - RS e as suas relações com as alterações geomorfológicas da enxurrada de 15 de novembro de 2010. Revista do Centro de Ciências Naturais e Exatas, Santa Maria, v. 37, n. 3 p.311-328, set./dez., 2015. 
OLIVEIRA, R.; D'ABREU, A. C.; SANTOS, J. C. Que multifuncionalidade? Uma abordagem aplicada ao ordenamento e gestão da paisagem. In: CONGRESSO DE ESTUDOS RURAIS, 3., Anais... Faro, Portugal: Universidade de Algrave, 2008, p. 1-15.

PINTO-CORREIA. T. Multifuncionalidade da paisagem rural: novos desafios à sua análise. Inforgeo, Lisboa, v. 20/21, p 67-71, jul.2007.

PREFeitura municipal de ARROIO DO PADRE. Plano Ambiental Municipal de Arroio do Padre-RS, 2014.

VERDUM, R.; VIEIRA L. F. S.; PIMENTEL, M. R. As Múltiplas Abordagens para o Estudo da Paisagem. Espaço Aberto, Rio de Janeiro, v.6, n.1, p.131-150, 2016. 